\title{
The effect of students' perceptions of Internet information quality on their use of Internet information in inquiry-based learning
}

\author{
Jacky Pow and Sandy C. Li \\ Hong Kong Baptist University
}

\begin{abstract}
In Web 2.0 environments, the quality of published information can vary significantly and much of the information on the Internet is unproven. This unverified information hinders rather than facilitates student learning, especially among undergraduate students who depend heavily on Internet resources for their studies. Currently, we do not have clear understanding of how students assess information quality and how this process affects their learning. This study argues that students' perceptions of Internet information quality influence their use of Internet information in their learning. The objectives of this research were to improve our understanding of how students evaluate Internet information by examining their perceptions of information quality and their use of information in learning, and to develop an information acceptance model that effectively measures and predicts students' use of Internet information. The study participants were undergraduate students at a Hong Kong university ( $\mathrm{n}=299)$. We used confirmatory factor analysis and structured equation models to develop an information acceptance model based on Klein's (2002) 15 information quality dimensions. Our results suggested that 8 out of the 15 information quality dimensions were significant in predicting students' use of Internet information in their academic work.
\end{abstract}

\section{Introduction}

Due to the ease of publishing information online in the Web 2.0 environment, information is being added to the Web at an amazing rate. The quality of this information varies significantly and many students find it difficult to differentiate fact from opinion (Eagleton \& Dobler, 2007). Much of the information we can now acquire from the Internet is unproven. This large quantity of unverified information hinders rather than facilitates students' inquiry-based learning (Pow, Li, \& Fung, 2009). This is especially the case for university students who are heavily dependent on Internet resources for their studies.

The rapid increase in the amount of information available on the Internet has created a number of problems. One that has caught the attention of educators is the increasing probability that students will use unverified information in their research (Klein, 2002).

Web 2.0 has not just increased social media and social interactivity, it has promoted the phenomenon of self-publishing or blogging. There are a growing number of academic blogs that serve as a platform for the exchange of academic- and discipline-related ideas (Luzón, 2012). Many academics have started to disseminate their research ideas or initial research findings on blogs. Students who come across these academic blogs may be tempted to use the information, as they are usually written in a scholarly style. However, Saper (2006) stated that academic blogs that do not go through an editorial or peer review process should not be seen as contributions to a discipline's knowledge production or have any influence on scholarship. Kirkup (2010) also pointed out that the content in these academic blogs may be either unverified or unverifiable. In this environment, students may find it difficult to choose appropriate sources for their academic work.

This study examines the relationship between students' perceptions of Internet information quality and how they use or discard information during inquiry-based learning. The results are expected to be useful for teachers who are designing inquiry-based learning activities and related assessments, as a better understanding of students' perceptions will help teachers to provide better guidance in the use of Internet information. This study examines students' perceptions of information quality and their use of information in inquiry-based learning, and develops an information acceptance model (IAM) that effectively measures and predicts students’ Internet information choices. 


\section{Students' inquiry learning and information literacy}

Increasingly more education theorists believe that inquiry learning is superior to traditional teaching, as it engages students in authentic investigations of real issues and phenomena, and allows them to develop intellectual skills and generate new knowledge on their own (Brickman, Gormally, Armstrong, \& Hallar, 2009; Freeman \& Taylor, 2006). Inquiry learning is highly encouraged in university studies as a result of the growing acceptance of student-centred learning (Levy, 2012). For instance, Healey and Jenkins (2009) argued that undergraduate students in tertiary education institutions should experience learning through research and inquiry. Although Cox, Levy, Stordy, and Webber (2008) believed there is more than one design protocol for inquiry learning, they asserted that there should be standard processes involved in the design and facilitation of all inquiry leaning activities. The five essential processes are: (1) engaging students in questions, (2) using evidence to respond to questions, (3) formulating explanations on the basis of evidence, (4) connecting explanations to knowledge, and (5) communicating and justifying explanations (Bransford, Brown, \& Cocking, 2000; Wiley et al., 2009). In their study, they showed that the design of inquiry-based learning could be innovative if it contained the basic components of inquiry learning. The distinctive features in their design included:

[S]ituating the inquiry task at the centre of the students' experience; identifying a task that requires student engagement with authentic inquiry practices of their discipline; providing for "process support" in areas such as information literacy development as well as discipline-based methodologies and techniques; providing activity-sequencing that is appropriate to an emergent process of discovery (Cox et al., 2008; p.7.)

The primary goal of inquiry learning is to let students learn how to conduct a systematic inquiry in which learning takes place (Cox et al., 2008; Kuhn, 2005). Students learn how to handle information by searching, categorising, prioritising, rearranging, analysing, evaluating and presenting information (Pow et al., 2009) and must demonstrate their abilities in each of these areas. Analogously, the Association of Colleges and Research Libraries (ACRL) pointed out that information literacy is the ability to use information technology to achieve an academic, work-related or personal goal by locating, evaluating, managing, and effectively using the needed information (Lee \& Leung, 2012). Students in this information age are required to master both inquiry and information literacy skills to succeed in their studies. According to the ACRL, a person with information literacy should possess the abilities to (1) determine the extent of information needed, (2) access the needed information effectively and efficiently, (3) evaluate information and its sources critically, (4) incorporate selected information into one's knowledge base, (5) use information effectively to accomplish a specific purpose, and (6) understand the economic, legal, and social issues surrounding the use of information, and thus access and use information ethically and legally (Gross \& Latham, 2009). The more efficiently students handle information, the more efficiently they learn. Among these information handling abilities, the ability to critically evaluate information is inarguably the key to success in inquiry-based learning. With the development of Internet technology, information has become more easily accessible. Students are encouraged to make clever choices of Internet resources in their assignments. The ability to evaluate Internet information is thus crucial for student success (Kim \& Sin, 2011). Although studies have indicated that the development of information skills should start in secondary schooling or earlier (Julien \& Barker, 2009), higher education settings in which students adopt an inquiry-based learning model are suitable environments for developing information literacy (Wiley et al., 2009).

\section{Internet information quality}

Information quality has received much attention from information science researchers and has become a large research area in the field of information systems (Strong, Lee, \& Wang, 1997a). Early studies, like Zmud's (1978) attempt to identify and categorise the different dimensions of information quality, paved the way for research in this area. Subsequently, a number of studies have developed frameworks to categorise and measure information quality (Lillank, 2003; Pipino, Lee, \& Wang, 2002; Strong, Lee, \& Wang, 1997b). For example, Davis and Olson (1985) discussed the roles of accuracy, precision and completeness of data in determining the quality of information systems. In the early 1990s, Fox, Levitin, and Redman (1993) and Huh, Keller, Redman, and Watkins (1990) proposed accuracy, completeness, consistency and currency as dimensions of data or information quality, although there were slight differences in their interpretations of the dimensions. In response to the development of information 
technology and the diversifications of information systems, Wand and Wang (1996) suggested that a definition of information quality should be task-independent and applicable across different systems irrespective of their functions and purposes. This has paved the way for the development of a more comprehensive framework for analysing information quality.

Klein (2002) examined students' perceptions of the quality of information found on the Internet. She pointed out that Internet data quality was a concern because information published on the Internet may not have been reviewed and that problems may occur when students use unverified information. She asserted that the information used by students in their academic work was not necessarily quality information, as it may not have been verified. The information quality dimensions in the frameworks only described students' perception of the quality of the information and did not describe the actual quality of the information. A piece of information should only be considered actual quality information when it is verified and appropriately used.

Kim and Sin (2011) explored the criteria that students consider important when selecting information. They scrutinised students' perceptions of different information sources in relation to their information selection behaviour. Their study revealed that there were discrepancies between what the students should have done and what they did do when selecting Internet information, perhaps because the students simply did not know what constituted good information sources and how to evaluate the quality of information (Kim \& Sin, 2011). This inability to select good information sources may be due to students' poor information literacy (Gross \& Latham, 2009). It seems that many university students simply do not realise the value of peer-reviewed resources (Burton \& Chadwick, 2000). Something has to be done about their perceptions of information sources and their actual use of information (Wei \& Zhang, 2008). Faculty members need to develop students' abilities to evaluate information quality if inquiry-based learning is to be used as a key learning approach in university education (DaCosta, 2010).

\section{Emerging problems}

It has been argued that university students should have mastered the inquiry and information literacy skills needed to produce academic work in this information age before they reach university. Unfortunately, it seems that teaching of these two sets of skills has not been seriously addressed and we cannot assume that university students are equipped with these skill sets. With the increasing use of inquiry-based learning in university settings, students are asked to search for information in available sources and then to analyse, evaluate and use this information in their assignments. Students' use or rejection of a piece of Internet information in their academic projects may reflect their previous experience and expectations of the Internet. Wei and Zhang (2008) found that users' expectations about the quality of information on the Internet, including perceived ease of use (PE) and perceived usefulness (PU), affected their selection of Internet information. Therefore, instructors should ensure that students select and use Internet information with caution and are aware of the issues relating to the use of unverified Internet sources in their learning.

Clearly, there is a gap between students' perceptions of information quality and their actual use of information. This study explores how information quality dimensions can predict students' actual use of information in their inquiry-based learning activities. The results will help instructors to design learning tasks for students' inquiry-based learning. They may also raise student awareness of the appropriate uses of Internet information in their academic work.

\section{Information acceptance model framework}

Researchers have recently begun to examine students' use of Internet information in their learning (Rieh, 2002). Lee, Cheung, and Chen (2005) studied students' acceptance of an Internet-based learning medium. They used a technology acceptance model (TAM) (Davis, 1989) to demonstrate that students' perceived usefulness (PU), perceived ease of use (PE) and perceived enjoyment (intrinsic motivation) were determinants of students' information acceptance (i.e., the tendency to use the information). This work provided a precedent for applying the TAM to educational settings.

The TAM (Davis, 1989) was derived from social cognitive theory and decision-making theories and uses two perceived characteristics to predict the acceptance of information technology (Straub, 2009). The 
model presumes that a technology's PU and PE will influence users' attitudes and will eventually affect their behavioural intentions. Davis (1989) defined PU as the extent to which a person believes that using a technology will enhance his or her work performance. In our case, the technology is the Internet and work performance is the student's academic performance. PE is defined as the degree to which a person believes that using a technology will be free of effort. The easier it is for a person to use a technology, the higher the chance the person will find it useful (Yusoff, Muhammad, Zahari, Pasah, \& Robert, 2009). These two constructs are believed to significantly influence the actual use of a technology. We examined the inter-relationship of these two constructs and their counterparts of actual use, actual usefulness (AU) and actual ease of use (AE).

As Chongsuphajaisiddhi and Chutimaskul (2007) indicated, information is part of an information system that consists of people, information, process and quality. They argued that the TAM can be used to show user acceptance of information. In their study of information acceptance in relation to information quality, Chongsuphajaisiddhi and Chutimaskul (2007) modified the TAM to create the information acceptance model (IAM) (Figure 1). We aim to test these perceived information quality constructs (PU and PE), against the corresponding actual information use constructs, actual usefulness (AU) and actual ease of use (AE).

Perceived Usefulness (PU) Intrinsic Information Quality Accuracy

Believability

Consistent content

Objectivity

Reputation

\begin{tabular}{cc}
\hline Contextual Information Quality & Representational Information Quality \\
\hline Amount of information & Concise representation \\
Completeness & Consistent representation \\
Compliance & Ease of manipulation \\
Efficiency & Interpretability \\
Relevancy & Understandability \\
Timeliness & \\
Value-added &
\end{tabular}

Perceived Ease of Use (PE) Accessibility Information Quality Accessibility Security

Figure 1. The Information Acceptance Model Framework (Chongsuphajaisiddhi \& Chutimaskul, 2007).

Chongsuphajaisiddhi and Chutimaskul's (2007) IAM is a modified version of a TAM that used 19 quality dimensions (Pipino et al., 2002). It was developed in an e-government context and these dimensions may not be suitable for an educational context.

Klein's (2002) developed a 15-dimension framework for measuring the perception of information quality in a group of university students. Klein's (2002) framework was based on Wang and Strong's (1996) 20dimension framework, which had Cronbach alpha values between .69 and .98, indicating a reasonable reliability. This suggested that Klein's framework would inherit the face validity and reliability of Wang and Strong's (1996) framework. We developed an IAM based on Klein's (2002) framework that effectively measures and predicts undergraduate students' Internet information choices in inquiry-based learning. Figure 2 shows the quality dimensions and their items. 
Perceived Usefulness (PU)

Actual Usefulness (AU)

\begin{tabular}{cc}
\hline \multicolumn{2}{c}{ Intrinsic Information Quality (IIQ) } \\
\hline Accurate (P01) & Accurate (U01) \\
Believable (P03) & Believable (U03) \\
Objective (P05) & Objective (U05) \\
Reputable (P07) & Reputable (U07) \\
\hline \multicolumn{1}{c}{ Contextual Information Quality (CIQ) } \\
\hline In appropriate amount (P02) & In appropriate amount (U02) \\
Complete (P04) & Complete (U04) \\
Relevant (P06) & Relevant (U06) \\
Timely (P08) & Timely (U08) \\
Value-added (P09) & Value-added (U09) \\
\hline Perceived Ease of Use (PE) & Actual Ease of Use (AE) \\
\hline Accessible (P10) & Accessible (U10) \\
Secured (P11) & Secured (U11) \\
\hline Representational Information Quality (RIQ) \\
\hline Concisely represented (P12) & Concisely represented (U12) \\
Easily understandable (P13) & Easily understandable (U13) \\
Interpretable (P14) & Interpretable (U14) \\
Consistently represented (P15) & Consistently represented (U15)
\end{tabular}

Figure 2. Klein's (2002) information quality dimensions and their items, with dimension and item codes

The proposed model is shown in Figure 3. We hypothesise that the proposed IAM will help to estimate students' Internet information acceptance and hence their actual use. We tested the 15 items with a confirmatory factor analysis to determine which items had a significant factor loading and should thus be incorporated into the model. We used an empirical test to develop our understanding of undergraduates' use of information in relation to their inquiry learning activities. The specific hypotheses are as follows:

H1. There is a positive relationship between the PU and AU of information in inquiry learning

H2. There is a positive relationship between the PE and AE of information in inquiry learning

H3. There is a positive relationship between the PE and AU of information in inquiry learning

H4. There is a positive relationship between the PU and AE of information in inquiry learning

H5. There is a positive relationship between the AU and AE of information in inquiry learning

H6. There is a positive relationship between the $\mathrm{AE}$ and $\mathrm{AU}$ of information in inquiry learning

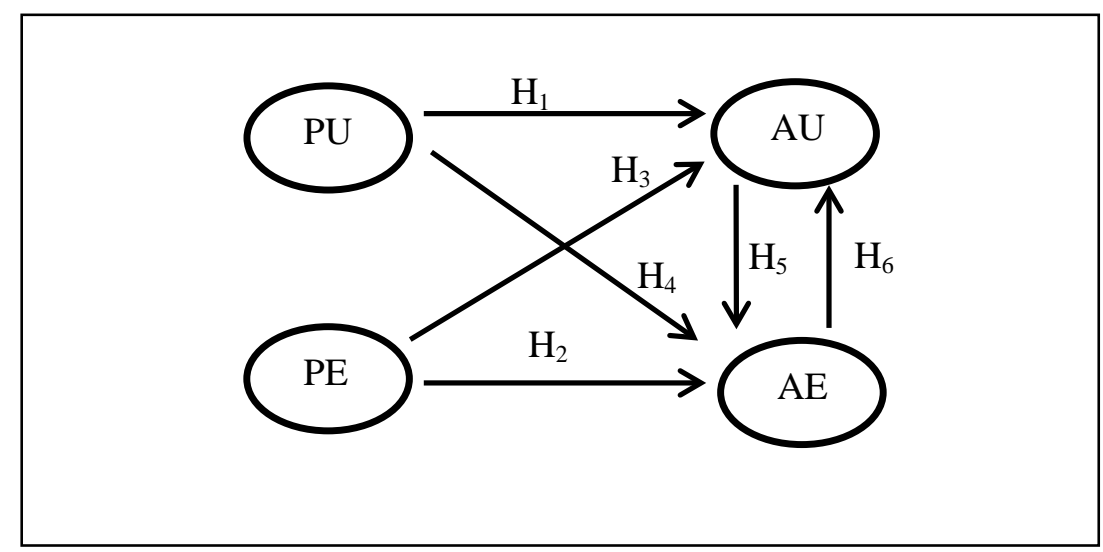

Figure 3. The proposed IAM 


\section{Methods}

\section{Participants}

We invited 300 undergraduate students from a local university in Hong Kong to participate in this study. We used stratified sampling to ensure that participants from most of the fields in the university were included. The fields of studies included arts, business, science, social sciences (including communication) and Chinese medicine (Table 1). However, as it was difficult to recruit participants in some fields of study, we did not intentionally control the number or gender of the participants in each field. Therefore, the sample was not evenly distributed across fields or gender.

Table 1

Field of study and gender distribution of the participants

\begin{tabular}{lllllll}
\hline & \multicolumn{7}{c}{ Field of study } \\
& Arts & Business & Science & $\begin{array}{l}\text { Social } \\
\text { Sciences }\end{array}$ & $\begin{array}{l}\text { Chinese } \\
\text { Medicine }\end{array}$ & Total \\
\hline Male & 16 & 7 & 21 & 47 & 15 & 106 \\
Female & 57 & 11 & 16 & 82 & 27 & 193 \\
Total & 73 & 18 & 37 & 129 & 42 & $\mathbf{2 9 9}$ \\
Percentage & $24.4 \%$ & $6 \%$ & $12.4 \%$ & $43.2 \%$ & $14 \%$ & $100 \%$ \\
\hline
\end{tabular}

We distributed the questionnaires with the help of course instructors. The participants were asked to complete a 30-item questionnaire (15 items examining their perceptions of information quality and 15 items examining their actual information use); their participation in the survey was voluntary. The participants were asked to return the survey to the instructor immediately upon completion. This ensured a high return rate. We received 299 valid questionnaires.

\section{The instrument}

The questionnaire was developed from Klein's (2002) framework. It was the main research instrument for measuring the relationship between the students' perceptions of information quality and their actual information use. On the cover of the questionnaire, the name of the researchers' department, the study title and the main purpose of the study were clearly stated. The participants were told that the questionnaire was anonymous and the data would be destroyed 6 months after the completion of the study. These procedures were done to uphold the research ethics and to increase the face validity and reliability of the questionnaire survey.

A pilot study with 10 participants (2 from each field) was conducted to increase the face validity of the questionnaire. The results of the pilot test were used to clarify those items that were not clear to the participants. For example, without unnecessary information was added to the description of the item concisely represented to help discriminate the item. The questionnaire first collected demographic data. It then gathered the students' perceptions of each quality dimension. Previous research has shown that there is practically no difference in the psychometric properties of scales using 4, 5 or 6 categories to measure psychoeducational constructs if the scale is an appropriate length and item discrimination is high (Lee \& Paek, 2014). In this study, as the scale length is not high (not more than 10 items in each dimension) and the item discrimination is not high, we used a 6-point Likert-type rating scale to prevent the students from choosing the indifferent middle option without much consideration of their answer. Our intention was to compel the students to take a definite position so that the results would give a clearer picture of their perceptions. We used a common statement to gather data on the perceived information quality dimensions of Internet information; the only change was the information quality dimension label in each statement. For example, the perception of accuracy was investigated with the following item:

In general, information on the Internet is:

Accurate-Strongly Disagree 123456 Strongly Agree

We began the statement with "in general" and gave the participants some flexibility in interpreting the statement, so their answers could refer to any information on the Internet. However, it is possible that the participants may have considered only information for learning, as we listed our project aims and 
mentioned that we were studying students' perceptions of Internet information quality and inquiry learning on the cover page of the questionnaire.

The questionnaire then collected data on the participants' actual use of information when engaged in inquiry learning. We again used a 6-point Likert-type scale and a common statement.

Recalling your last course inquiry project that used the Internet as an information source, do you agree that the Internet information you used in the project is:

Accurate - Strongly Disagree 123456 Strongly Agree

The items in each section were slightly rearranged so that the participants were not aware of the underlying constructs, thus revealing the relationships between the sub-constructs and increasing the reliability of the study.

\section{Data analysis}

We explored whether the students' perceptions of information quality were related to their actual use of information in their inquiry projects. We used a modified IAM (Chongsuphajaisiddhi \& Chutimaskul, 2007) containing Klein's (2002) information quality dimensions, derived from the TAM (Davis, 1989), as our theoretical framework (Figure 3).

We used a confirmatory factor analysis to test the validity of the information quality dimensions in the constructs. We conducted a two-way multivariate analysis of variance on the participants' fields of study and genders to identify any differences in the mean scores of PU, PE, AU and AE. We used structured equation modelling to test the model fit for students' acceptance. These findings gave us insights into the students' perceptions of the information they found on the Internet during their inquiry activities.

\section{Results}

\section{Confirmatory factor analysis}

LISREL 8.8 was used to conduct a confirmatory factor analysis examining the validity of the information quality dimensions in the constructs. A parsimonious set of items for each construct was identified to ensure that both convergent and discriminant validity were observed. The items with a factor loading lower than 0.6 were eliminated and this condition reduced the number of information quality dimensions in the perceived information quality from 15 to 8 . Believable was cut from the intrinsic information quality. Timely and value-added were removed from the contextual information quality. Accessible and secured were removed from the accessibility information quality. Concisely represented and easily understandable were excluded from the representational information quality. As a result, the fitting indices, NFI, NNFI, CFI, GFI and AGFI, ranged from 0.94 to $0.98(>0.9)$, and the root mean square error of approximation (RMSEA) was $0.0657(<0.08)$, indicating that the measurement model was of good fit. Table 2 shows the factor loading of each information quality dimension in the four constructs, PU, PE, AU and AE. The fitting indices (shown in Table 3) indicated that the measurement model had a good-fit. The value of the Satorra-Bentler $\chi^{2}$ was 224.23, with a corresponding p-value less than 0.001 . The root mean square error of approximation value was 0.0657 , which was less than the 0.08 cut-off. The fitting indices, such as the normed fit index, non-normed fit index, comparative fit index, incremental fit index, relative fit index, goodness of fit index and adjusted goodness of fit index were all well above 0.9 . 
Table 2

Parameter estimates for the confirmatory factor analysis measurement model

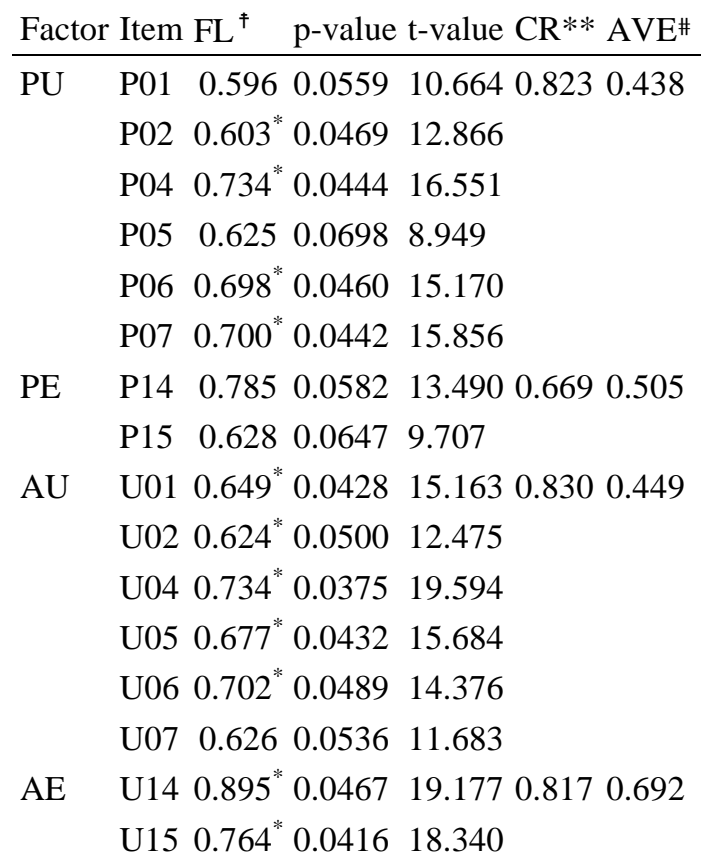

AVE: average variance extracted; CR: composite reliability; FL: factor loading; ${ }^{*} \mathrm{p}<.05$

Table 3

A Summary of fitting indices of the structural equation models

\begin{tabular}{|c|c|c|c|c|c|}
\hline Goodness of fit index & $\begin{array}{l}\text { Measurement } \\
\text { Model }\end{array}$ & Model 1 & Model 2 & Model 3 & Model 4 \\
\hline Satorra-Bentler chi-square (df) & $\begin{array}{l}224.230 \\
(98)\end{array}$ & $\begin{array}{l}285.272 \\
(101)\end{array}$ & $\begin{array}{l}285.066 \\
(100)\end{array}$ & $\begin{array}{l}251.441 \\
(100)\end{array}$ & $\begin{array}{l}230.817 \\
(99)\end{array}$ \\
\hline p-value of chi-square test & 0.00 & 0.0 & 0.0 & 0.0 & 0.00 \\
\hline $\begin{array}{l}\text { Root mean square error of } \\
\text { approximation }\end{array}$ & 0.0657 & 0.0782 & 0.0788 & 0.0713 & 0.0668 \\
\hline Normed fit index (NFI) & 0.950 & 0.936 & 0.936 & 0.943 & 0.948 \\
\hline $\begin{array}{l}\text { Non-normed fit index } \\
\text { (NNFI) }\end{array}$ & 0.964 & 0.949 & 0.949 & 0.958 & 0.963 \\
\hline $\begin{array}{l}\text { Parsimony normed fit index } \\
\text { (PNFI) }\end{array}$ & 0.775 & 0.788 & 0.780 & 0.786 & 0.782 \\
\hline Comparative fit index (CFI) & 0.971 & 0.957 & 0.957 & 0.965 & 0.970 \\
\hline Incremental fit index (IFI) & 0.971 & 0.958 & 0.957 & 0.965 & 0.970 \\
\hline Relative fit index (RFI) & 0.938 & 0.924 & 0.923 & 0.932 & 0.937 \\
\hline $\begin{array}{l}\text { Standardised root mean } \\
\text { square residual }\end{array}$ & 0.0653 & 0.0864 & 0.0862 & 0.0749 & 0.0671 \\
\hline Goodness of fit index (GFI) & 0.978 & 0.961 & 0.961 & 0.971 & 0.977 \\
\hline $\begin{array}{l}\text { Adjusted goodness of fit } \\
\text { index (AGFI) }\end{array}$ & 0.969 & 0.948 & 0.947 & 0.961 & 0.968 \\
\hline $\begin{array}{l}\text { Expected cross-validation } \\
\text { index }\end{array}$ & 1.007 & 1.192 & 1.198 & 1.085 & 1.023 \\
\hline Akaike information criterion & 300.230 & 355.272 & 357.066 & 323.441 & 304.817 \\
\hline $\begin{array}{l}\text { Consistent Akaike's } \\
\text { information criterion }\end{array}$ & 478.847 & 519.788 & 526.282 & 492.657 & 478.734 \\
\hline
\end{tabular}


Table 4

Squared inter-construct correlation coefficients(SIC)

\begin{tabular}{lllll}
\hline & PU & PE & AU & AE \\
\hline PU & & 0.419 & 0.465 & 0.122 \\
PE & 0.419 & & 0.292 & 0.546 \\
AU & 0.465 & 0.292 & & 0.508 \\
AE & 0.122 & 0.546 & 0.508 & \\
\hline Average SIC & 0.34 & 0.42 & 0.42 & 0.39 \\
\hline
\end{tabular}

The eight items retained for model building were accurate (P1), in appropriate amount (P02), complete (P04), objective (P05), relevant (P06) and reputable (P07) in the PU construct and interpretable (P14) and consistently represented (P15) in the PE construct. The retained items in the perceived constructs were then used to build models that predicted the actual constructs.

\section{Convergent and discriminant validity}

We examined the extent to which the indicators of a specific construct converged or shared a high proportion of common variance by assessing the factor loadings, average variance explained and composite reliability of each construct. The results are given in Table 2 . The results indicated that most of the factor loadings were significant, as only a few had p-values slightly above 0.05 . The average factor loadings were well above the threshold value of 0.5 . The composite reliability scores ranged from 0.67 to 0.83 and each construct's average variance explained (AVE) was either close to or above 0.5. The convergent validity of the constructs was therefore established, as according to Fornell and Larcker (1981), if the overall composite reliability is higher than 0.6 and the average variance explained of each construct is higher than 0.4 , the convergent validity of the construct can be considered as adequate, although not rigorous. Having an AVE between $0.4-0.5$ indicates that the average factor loading of the items varies from 0.6 to 0.7 , signifying strong association between the latent construct and its corresponding indicators.

We further examined the extent to which each construct was distinct from the other constructs by comparing the average variance explained and the squared inter-construct correlation coefficient estimates. The average squared inter-construct correlation coefficients ranged from 0.34 to 0.42 and were smaller than the average variance explained estimates (Table 4). The indicator variables therefore had more in common with the constructs that they were associated with than with the other constructs, indicating that the discriminate validity of the model was adequate.

\section{Multivariate analysis of variance}

Table 5a shows the results of a two-way multivariate analysis of variance on gender and field differences in the mean scores of PU, PE, AU and AE. The p-values (final two columns) indicated that there were no gender differences. However, significant field differences were found in the PU and AU. The participants' genders and fields of study had no significant effects on the PE and AE.

Table 5b shows the results of a post-hoc comparison. A significant difference in the PU mean scores was found between the arts group and the Chinese medicine group and between the social sciences group and the Chinese medicine group. A significant difference in the AU mean scores was found between the arts group and the science group. The arts and social sciences students tended to have less positive perceptions of the usefulness of Internet information and less satisfactory experiences in using Internet information in their work than the students from science-oriented disciplines. 
Table 5a

A two-way multivariate analysis of variance of the field and gender differences in the mean scores of the four constructs

\begin{tabular}{cclc}
\hline Construct & Mean score & \multicolumn{2}{c}{$p$-value } \\
& & Field & Gender \\
\hline PU & 20.9 & $0.03^{*}$ & 0.86 \\
PE & 7.77 & 0.21 & 0.08 \\
AU & 22.5 & $0.01^{*}$ & 0.70 \\
AE & 7.88 & 0.20 & 0.77 \\
\hline
\end{tabular}

Table 5b

A post-hoc comparison of the mean scores in the different fields

\begin{tabular}{cccccc}
\hline Construct & \multicolumn{5}{c}{ Mean score in different fields } \\
& Arts & Business & Science & $\begin{array}{c}\text { Social } \\
\text { Sciences }\end{array}$ & $\begin{array}{c}\text { Chinese } \\
\text { Medicine }\end{array}$ \\
\hline PU & $20.3^{*}$ & 21.0 & 21.5 & $20.4^{*}$ & $22.4^{*}$ \\
AU & $21.4^{+}$ & 23.7 & $23.8^{+}$ & 22.5 & 22.6 \\
\hline
\end{tabular}

*A significant difference in the mean scores was found between arts and Chinese medicine and between social sciences and Chinese medicine.

${ }^{+}$A significant difference in the mean scores was found between arts and science.

\section{Structural equation modelling}

Using the dimensions remaining after the confirmatory factor analysis, we explored the interaction between the perceived and actual constructs by building different structural equation models. Based on the fitting indices, four plausible structural equation models were identified. The Satorra-Bentler $\chi^{2}$ value of the four models ranged from 230 to 285 with corresponding p-values less than 0.001 , and the root mean square error of approximation value ranged from 0.067 to 0.086 . In addition, the fitting indices, such as the normed fit index, non-normed fit index, comparative fit index, incremental fit index, relative fit index, goodness of fit index and adjusted goodness of fit index were all well above 0.9. Model One (Figure 4) was used to examine the relationships between the two perceived constructs and the corresponding actual constructs, i.e., the effect of the PU on the AU and the effect of the PE on the AE. Model Two (Figure 5) was built to examine the effect of the PU on the AU and the AE. Model Three (Figure 6) was constructed to study the effect of the PE on the AU and the AE, and Model Four (Figure 7) was created to study the mutual dependence between the AU and AE. 


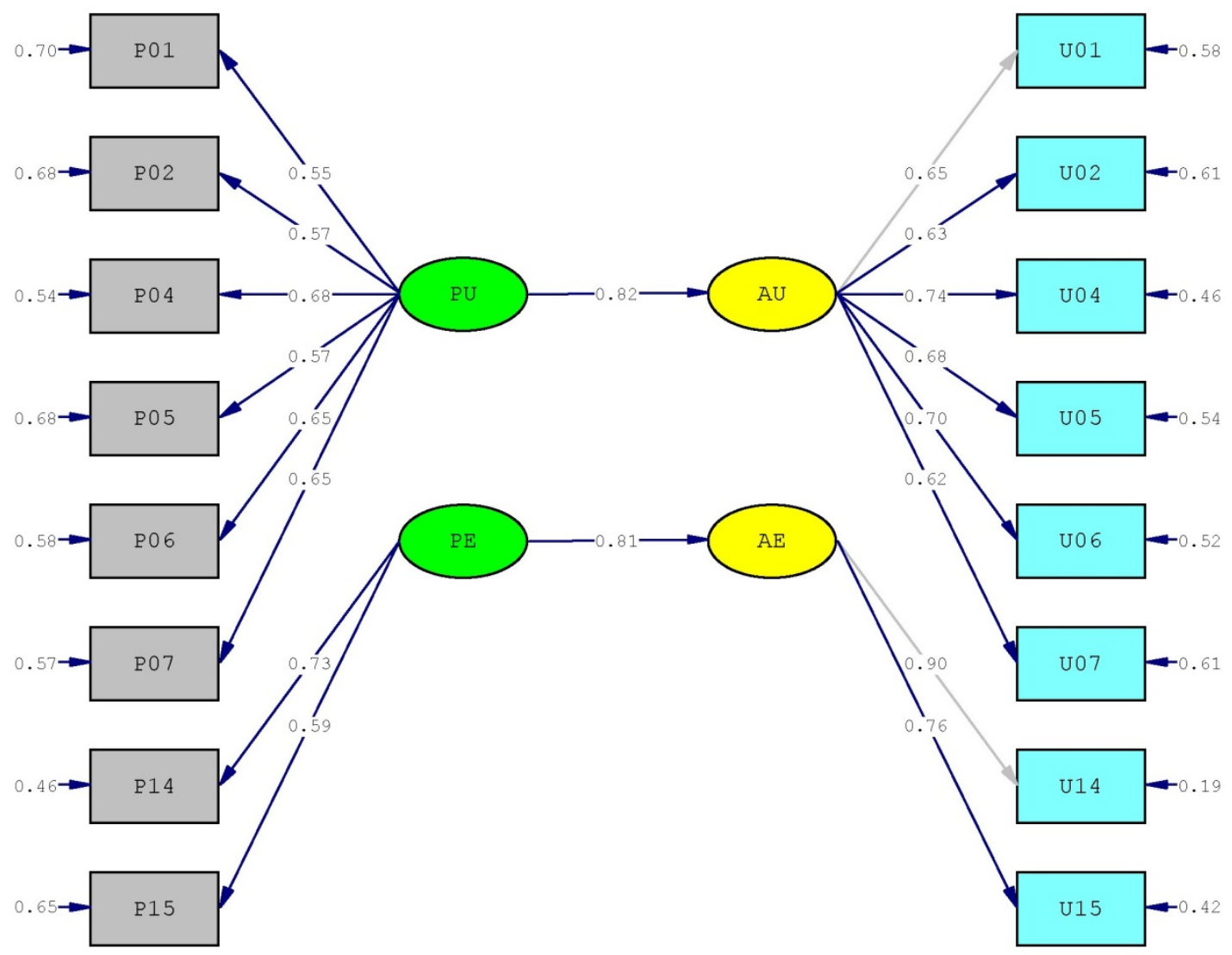

Chi-Square=285.27, df $=101, \mathrm{P}-\mathrm{value}=0.00000, \mathrm{RMSEA}=0.078$

Figure 4. Model One - a structural equation model examining the effects of the PU on the AU and the PE on the AE

\section{Model One}

Model One served as a base model to examine the effects of the PU on the AU $\left(\mathrm{H}_{1}\right)$ and the PE on the AE $\left(\mathrm{H}_{2}\right)$. It demonstrated that relationships existed between these constructs in some of the information quality dimensions in Klein's (2002) framework. As shown in Figure 4, there was a strong positive association between the PU and $\mathrm{AU}$ (0.82) and between the PE and $\mathrm{AE}$ (0.81). The information quality dimensions in the PU and PE had a set of good-sized loading factors. The students' perceptions of the usefulness and the ease of use of Internet information were therefore likely to affect their actual use and ease of use during their inquiry projects. 


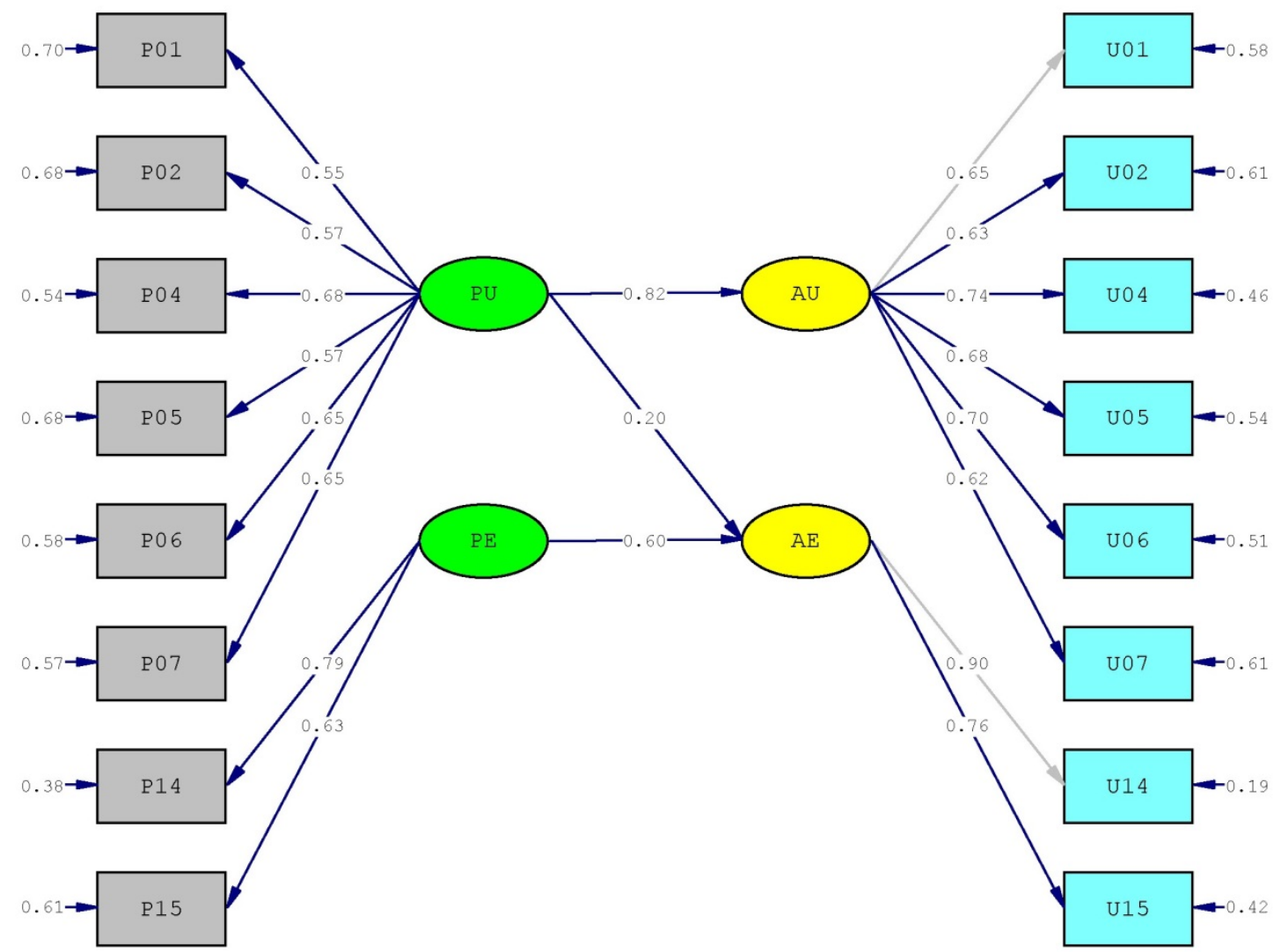

Chi-Square $=285.07, \mathrm{df}=100, \mathrm{P}-\mathrm{value}=0.00000, \mathrm{RMSEA}=0.079$

Figure 5. Model Two - a structural equation model examining the effects of the PU on the AU and AE

\section{Model Two}

In Model Two, we added a loading estimate from the PU to the $\mathrm{AE}\left(\mathrm{H}_{3}\right)$ to study the effect of the PU on both the AU and AE. The additional loading estimate of the PU on the AE was 0.2 and the loading of the PU on the AU dropped from 0.81 to 0.60 (Figure 5), suggesting that part of the AE variance could be explained by the PU. Interestingly, the loading estimate of the PU on the AU remained strong and remained at 0.82 . This model showed that students' perceived usefulness of information maintained the same great influence on students' actual use of information with respect to its usefulness (AU, refer to Model One) and also influenced ease of use (AE, although in a lower magnitude). At the same time, the influence of the perceived ease of use on the actual ease of use of information was reduced as a result of the inserted influence of the students' perceived usefulness on the actual ease of use. 


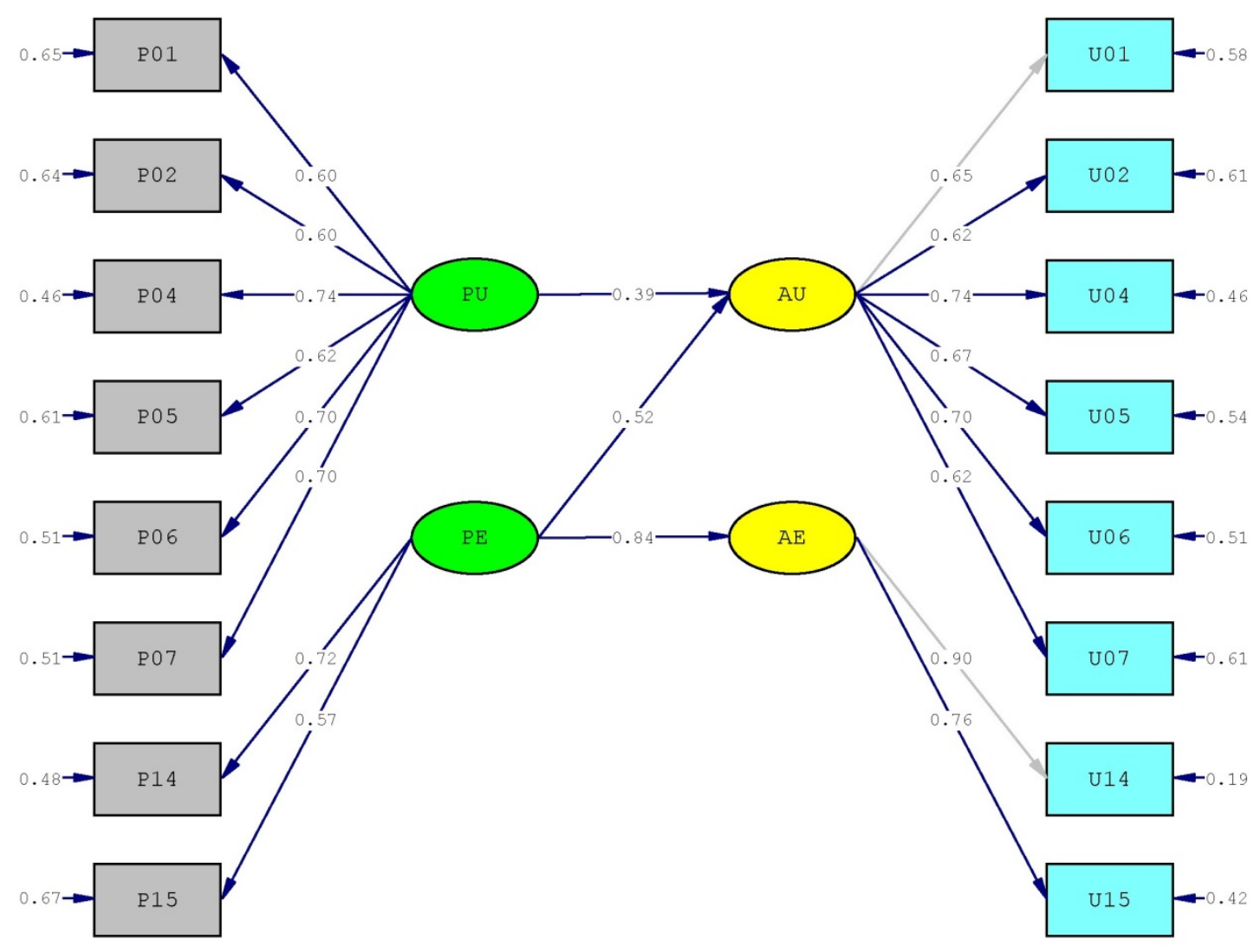

Chi-Square $=251.44, d f=100, P-v a l u e=0.00000$, RMSEA $=0.071$

Figure 6. Model Three - a structural equation model examining the effects of the PE on the AE and AU

\section{Model Three}

As in Model Two, we added a loading estimate from the PE on the AU $\left(\mathrm{H}_{4}\right)$ in Model Three to study the relationships between these constructs. The loading of the PU on the AU dropped from 0.82 to 0.39 (Figure 6). The loading estimate of the PE on the AU was 0.52, indicating the existence of a strong link between the PE and AU and that this link was stronger than the link between the PU and AU. The loading estimate of the PE increased from 0.81 to 0.84 . A greater part of the AE variance was therefore explained by the PE in this model. This indicated that students' perceived ease of use had a greater influence on the actual ease of use (refer to Model One) and a relatively high influence on the actual usefulness. As a result of the inserted influence of the perceived ease of use on the actual usefulness, the influence of the perceived usefulness was drastically reduced. 


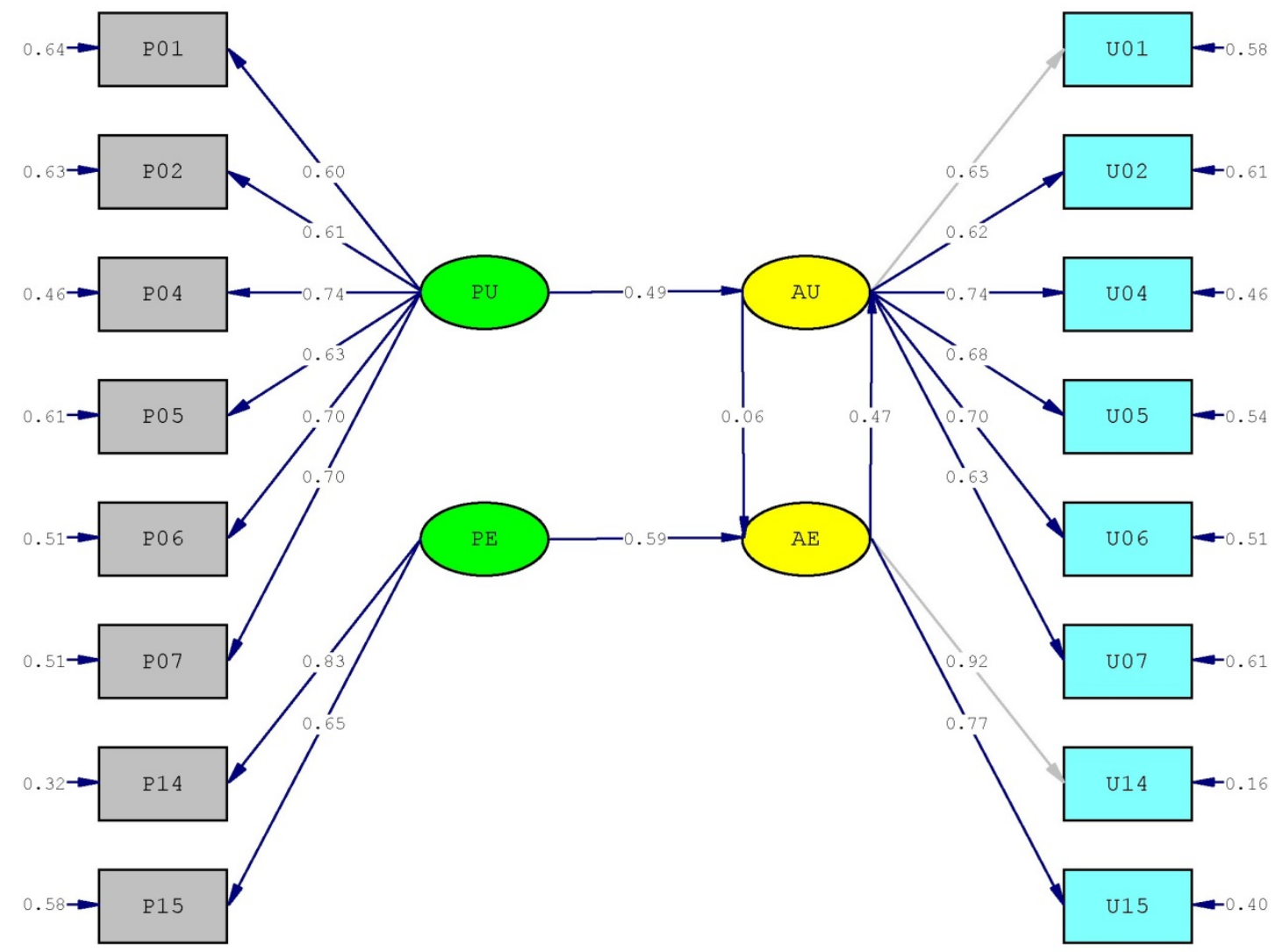

Chi-Square $=230.82, \mathrm{df}=99, \mathrm{P}-\mathrm{value}=0.00000, \mathrm{RMSEA}=0.067$

Figure 7. Model Four - a structural equation model examining the reciprocal effects of the AU and AE

\section{Model Four}

Model Four was constructed to investigate the existence of reciprocal relationships between the AU and AE. Figure 7 shows that the effect of the $A U$ on the $\mathrm{AE}\left(\mathrm{H}_{5}\right)$ was noticeably small $(0.06)$, whereas the effect of the $\mathrm{AE}$ on the $\mathrm{AU}$ (H6) was rather large (0.47). The AE therefore exerted a great influence on the AU, but the AE did not have a strong influence on the AU Furthermore the loading of the PU on the AU decreased from 0.82 to 0.49 and the loading of the PE on the AE decreased from 0.81 to 0.59 . These decreases were driven by the additional loading estimate of the AE on the AU. Figure 7 shows that part of the variance in explaining the actual usefulness was drawn to the actual ease of use, suggesting that the actual ease of use was an important factor in determining the actual usefulness of Internet information for students engaged in inquiry projects.

\section{Discussion and Implications}

This study used four models to explore students' perceptions of information quality and these perceptions' potential influence on inquiry learning. A confirmatory factor analysis of the information quality dimensions in Klein's (2002) framework reduced the number of information quality dimensions in our models to eight. We built structural equation models based on our hypotheses. The results of testing these models showed that all of the hypotheses could be accepted, except $\mathrm{H}_{5}$, which was rejected due to the small size of the corresponding loading estimate.

The four models provide some insights into how we can facilitate inquiry-based learning in the digital age. Figure 8 shows a model that combines the four structural equation models. 


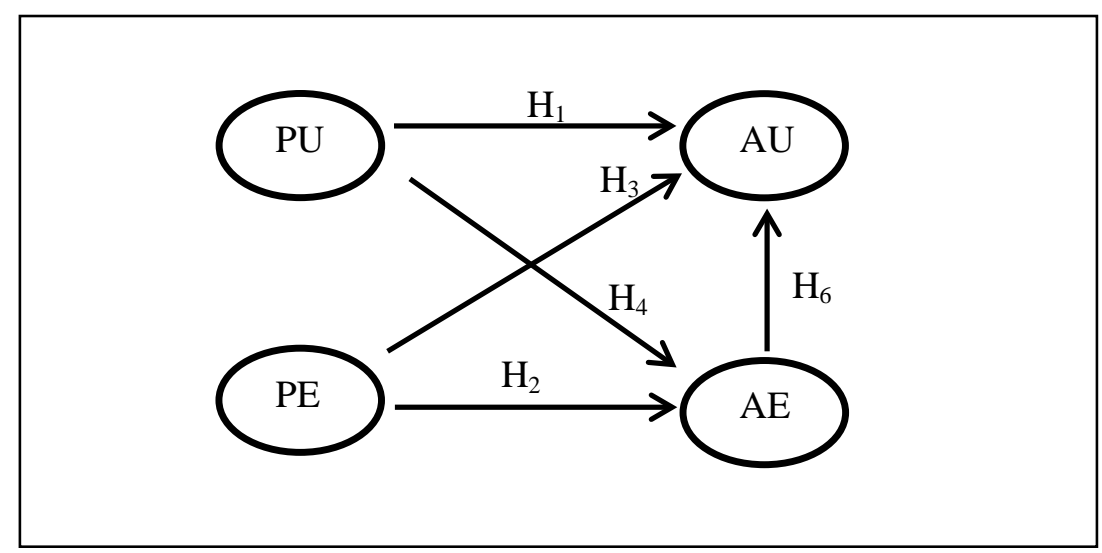

Figure 8. The model combining the four structural equation models

Model One demonstrated that the students' PU and PE had a direct effect on their AU and AE of Internet information. If university instructors can change students' perceptions of the quality of Internet information, it is likely that the students will change the way that they use Internet information in their inquiry projects. For example, instructors can explain how to search for reputable (P07) and interpretable (P14) information on the Internet by setting an assignment that requires the students to do so. This could be done by discussing with students what attributes a reputable website should possess. Students could then use these attributes to examine whether the Internet information they find is from reputable sources. Along the same line, university instructors can ask students to explain in their own words the Internet information they collect, to evaluate whether the information is interpretable to them. Moreover, they can share with their students how a perceived information quality, such as complete (P04), can change. A piece of information that is complete today may not be complete in the future, if more details are revealed. Instructors can use this model to develop a better understanding of how their students select and use Internet information in their academic work and can respond by providing more specific guidance when setting inquiry tasks. This guidance should not be provided by the instructors as part of the assignment instruction but should be developed with the students through discussion and careful examination of the information qualities.

We found cross-construct influences in our analysis: the PU had an effect on the AE and the PE had an effect on the AU. The cross-construct influence of the PE was stronger than that of the PU. The PE consisted of only two factors, whereas the PU consisted of six factors. The two factors in the PE, interpretable (P14) and consistently represented (P15), are therefore likely to be important factors in explaining the students' AU of Internet information in their inquiry projects. This is consistent with Kim and Sin's (2011) comment that the use of Internet information per se did not necessarily constitute a problem; it was the students' inability to evaluate sources that caused trouble. During the inquiry processes, systematic processing (evaluation or verification) of information is both time consuming and cognitively demanding (Hilligoss \& Rieh, 2008). As a result, students may not have the motivation or necessary cognitive power to verify the information that they collect. Hence, if convenience rather than usefulness is the criterion students are using to select information for their inquiry projects, their learning will be seriously affected (Biddix, Chung \& Park, 2011). This study provides evidence that students are inclined to select easy to use information over the better quality information that requires more effort to verify. Apparently, the 'principle of least effort' is prevalent when students are seeking information for their academic work (Bawden \& Robinson, 2009; Berryman, 2008). We echo Kim and Sin's (2011) concerns over students' attitudes in selecting information; they "hoped that students, in their prime time of pursuing knowledge, would engage in rigorous research for their academic work” (p.179).

It is reasonable to believe that students look for information that can be used instantly in their academic work with minimal difficulties (Warwick, Rimmer, Blanford, Gow, \& Buchanan, 2009). If a piece of information is not explained well or is not readily interpretable, but is considered useful, students may simply quote the information directly, rather than really digesting the content and rewriting it in their own words. This is not considered a proper use of information, as it reduces the chance of new learning and 
may also increase the risk of plagiarism. A more comprehensive information literacy education is called for at the institutional level. Faculty and librarians must make more concerted efforts to increase students' ability to use Internet information in their academic work (Kim \& Sin, 2011). Similarly, if information is not consistently represented (in a similar style), students are less likely to use it in their inquiry learning, as they may need to compile it again before it can be used, which reduces the ease of use of that piece of information. Instructors should therefore pay attention to the interpretable and consistently represented factors when they design inquiry learning activities. In practice, instructors can ask students to use online social annotation tools or discussion forums to seek help from their classmates when they come across obscure information during an inquiry project (Li, Pow, \& Cheung, 2015). Given the recent development in online annotation systems (Chao, Chen, \& Chang, 2010; Hoff, Wehling, \& Rothkugel, 2009), instructors can also encourage students to synthesise inconsistently represented information with these annotation systems, to increase the likelihood of use.

We found that the two perceived quality dimensions (accessibility and security) in the information accessible quality sub-construct did not have a significant effect on the AU or AE. The Internet is a public system and is more accessible than any other information system. Therefore, as these accessible quality dimensions did not have a strong association with the students' actual use of Internet information, the information quality dimensions were excluded from the models. The students seemed to believe that information on the Internet should be free and accessible at any time. They were aware that some information on the Internet is only available to authorised people and that they may sometimes need to pay for access, for example information in academic journal articles that require subscriptions. The students simply ignored such information and did not use it in their inquiry learning or academic work. This is certainly not the kind of learning experience that we want to see and we therefore need to educate students to make the best use of this quality information source. At the instructor level, information literacy education should be incorporated in the actual courses and at the institutional level, information literacy education should be integrated into the university-wide quality assurance mechanism.

We found that there were no significant gender differences in either the perception of Internet information quality or the actual use of Internet information. However, we found that students in the Arts and Social Sciences had lower means scores in their PU and AU. The students in the Arts and Social Sciences were less positive about the usefulness of Internet information and were therefore more cautious in their actual use of Internet information in their academic work.

\section{Concluding remarks}

In this study, we tried to deepen our understanding of students' perceptions of Internet information quality and their use of information in inquiry learning. We built an IAM to predict the pattern of Internet information use by undergraduate students. The findings suggested that the undergraduate students' perceptions of information quality did influence their choice of which Internet information to use in their inquiry projects. However, only some of the perceived information quality dimensions were found to be associated with actual use. For instance, the information quality dimensions believable (P03) and timely (P08) were found to be insignificant in predicting the students' use of Internet information in their academic work. The students were more inclined to select information that was interpretable (P14) and consistently represented (P15).

We used a confirmatory factor analysis and structural equation modelling to test which information quality dimensions affected the students' use of Internet information in their inquiry projects. We reduced Klein's (2002) 15 quality dimensions to 8. The information accessible quality sub-construct was eliminated from the proposed IAM due to its small effect size, leaving three sub-constructs in the IAM. We found that two information quality dimensions, interpretable (P14) and consistently represented (P15), in the PE construct were influential factors in the IAM. Six information quality dimensions in the PU construct were included in the model. Each of the PU information quality dimensions was therefore a relatively weaker factor in predicting the students' choice of Internet information than the two PE factors.

In summary, we expect that this IAM will help university instructors to facilitate their students' use of Internet information in their inquiry projects. However, given the bigger issue of students using poor quality, unverified information due to the emergence of Web 2.0, there is a need for efforts at the institutional level rather than at the individual instructor level to develop students' information literacy 
skills and Internet knowledge (Wei \& Zhang, 2008). We believe that a better integration of information literacy and inquiry-based learning into the curriculum is necessary not just to enhance learning and teaching at universities but also to equip students to be lifelong learners. The findings of our study may serve as a good reference or a starting point for such curricular changes.

\section{Limitations and Suggestions}

We asked the participating students to provide data describing their last inquiry project. The study's reliability would be improved by a more systematic collection of data over more projects and a longer period of time. Different participants may have different perceptions of inquiry learning. We may need to provide the participants with a clearer definition of inquiry learning before data collection.

Although we constructed an IAM, we found that students in different fields of study had different perceptions of Internet information and patterns of use. We should pay attention to this factor when developing suitable guidance for students in different fields of study. In this study, the different fields of study were not equally represented in the sample (the participants in social sciences outnumbered the other fields of study) and the findings may be affected as a result. This must be corrected in future studies.

We built our models using quantitative analyses and may have ignored some non-quantitative factors that affect students' perceptions and actions. For example, we are not certain whether the eight information quality dimensions identified in this study are beneficial to students' inquiry learning. Should students use information based largely on its interpretability and reputation, for instance, as the IAM predicts that they will? Our study did not scrutinise this aspect of the proper use of Internet information. The findings only showed the students' actual use of information and not how and why they used particular information in their academic projects. Further research on the appropriate choice of Internet information for students' inquiry learning based on the IAM is encouraged.

\section{References}

Bawden, D., \& Robinson, L. (2009). The dark side of information: Overload, anxiety and other paradoxes and pathologies, Journal of Information Science 35(2) 180-191. doi.org/10.1177/0165551508095781

Berryman, J. M. (2008). Judgements during information seeking: A naturalistic approach to understanding the assessment of enough information. Journal of Information Science 34(2) 196-206. doi.org/10.1177/0165551507082589

Biddix, J. P., Chung, P. J., \& Park, H. W. (2011). Convenience or credibility? A study of college student online research behaviors. Internet and Higher Education, 14(3), 175-182. doi.org/10.1016/j.iheduc.2011.01.003

Bransford, J. D., Brown, A. L., \& Cocking, R. R. (2000). How people learn: Brain, mind, experience, and school. Washington, DC: National Academy of Sciences.

Brickman, P., Gormally, C., Armstrong, N., \& Hallar, B. (2009). Effects of inquiry-based learning on students' science literacy skills and confidence. International Journal for the Scholarship of Teaching and Learning, 3(2), 1-22.

Burton, V. T., \& Chadwick, S. A. (2000). Investigating the practices of student researchers: Patterns of use and criteria for use of internet and library sources. Computers and Composition, 17(3), 309-328. doi.org/10.1016/S8755-4615(00)00037-2

Chao, P. Y., Chen, G. D., \& Chang, C. W. (2010). Developing a cross-media system to facilitate question-driven digital annotations on paper textbooks. Educational Technology \& Society, 13(4), 3849.

Chongsuphajaisiddhi, V., \& Chutimaskul, W. (2007). Information quality for local e-government. Journal of Global Management Research, Dec, 7-18.

Cox, A., Levy, P., Stordy, P., \& Webber, S. (2008). Inquiry-based learning in the first-year information management curriculum. Innovation in Teaching and Learning in Information and Computer Sciences, 7(1), 3-21. doi.org/10.11120/ital.2008.07010003

DaCosta, J. W. (2010). Is there an information literacy skills gap to be bridged? An examination of faculty perceptions and activities relating to information literacy in the United States and England. College \& Research Libraries, 71(3), 203-222. doi.org/10.5860/0710203

Davis, F. D. (1989). Perceived usefulness, perceived ease of use and user acceptance of information technology. MIS Quarterly, 13(3), 319-339. 
Davis, G. B., \& Olson, M. H. (1985). Management information systems: Conceptual foundations, structure, and development. New York, NY: McGraw-Hill.

Eagleton, M. B., \& Dobler, E. (2007). Reading the Web: Strategies for Internet inquiry. New York, NY: Guilford Press.

Fox, C., Levitin, A., \& Redman, T. (1993). The notion of data and its quality dimensions. Information Processing \& Management, 30(1), 9-19. doi.org/10.1016/0306-4573(94)90020-5

Freeman, G., \& Taylor, V. (2006). Integrating science and literacy instruction: A framework for bridging the gap. Lanham, MD: Rowman and Littlefield Education.

Fornell, C., \& Larcker, D. F. (1981). Evaluating structural equation models with unobservable variables and measurement error. Journal of Marketing Research, 18(1), 39-50.

Gross, M., \& Latham, D. (2009). Undergraduate perceptions of information literacy: Defining, attaining, and self-assessing skills. College \& Research Libraries, 70(4), 336-350. doi.org/10.5860/crl.70.4.336

Healey, M., \& Jenkins, A. (2009). Developing undergraduate research and inquiry. York: The Higher Education Academy.

Hilligoss, B., \& Rieh, S. Y. (2008). Developing a unifying framework of credibility assessment: Construct, heuristics, and interaction in context. Information Processing and Management, 44(4), 1467-1484. doi.org/10.1016/j.ipm.2007.10.001

Hoff, C., Wehling, U., \& Rothkugel, S. (2009). From paper-and-pen annotations to artefact-based mobile learning. Journal of Computer Assisted Learning, 25(3), 219-237. doi.org/10.1111/j.13652729.2008.00297.x

Huh, Y. U., Keller, F. R., Redman, T. C., \& Watkins, A. R. (1990). Data quality. Information and Software Technology, 32(8), 559-565. doi.org/10.1016/0950-5849(90)90146-I

Julien, H., \& Barker, S. (2009). How high-school students find and evaluate scientific information: A basis for information literacy skills development. Library \& Information Science Research, 31(1), 1217. doi.org/10.1016/j.lisr.2008.10.008

Kim, K.S., \& Sin, S.C.J. (2011). Selecting quality sources: Bridging the gap between the perception and use of information sources. Journal of Information Science, 37(2), 178-188. doi.org/10.1177/0165551511400958

Kirkup, G. (2010). Academic blogging: Academic practice and academic identity. London Review of Education, 8(1), 75-84. doi.org/10.1080/14748460903557803

Klein, B. D. (2002). Internet data quality: Perceptions of graduate and undergraduate business students. Journal of Business and Management, 8(4), 425-432.

Kuhn, D. (2005). Education for Thinking. London: Harvard University Press.

Lee, J., \& Paek, I. (2014). In search of the optimal number of response categories in a rating scale. Journal of Psychoeducational Assessment, 32(7), 663-673. doi.org/10.1177/0734282914522200

Lee, P., \& Leung, L. (2012). The influences of information literacy, internet addiction and parenting styles on internet risks. New Media and Society, 14(1), 117-136. doi:10.1177/1461444811410406

Lee, M. K. O., Cheung, C. M. K., \& Chen, Z. (2005). Acceptance of Internet-based learning medium: The role of extrinsic and intrinsic motivation. Information \& Management, 42(8), 1095-1104. doi.org/10.1016/j.im.2003.10.007

Levy, P. (2012). Developing inquiry-guided learning in a research university in the United Kingdom. In V. S. Lee (Ed.), Inquiry-Guided Learning (pp. 15-26). San Francisco, CA: Jossey-Bass.

Li, S. C., Pow, J. W. C., Cheung, W. C. (2015). A delineation of the cognitive processes manifested in a social annotation environment. Journal of Computer Assisted Learning, 31(1), 1-13. doi: 10.1111/jcal.12073

Lillank, P. (2003). The quality of information. International Journal of Quality and Reliability Management, 20(6), 691-703.

Luzón, M. J. (2012). Your argument is wrong: A contribution to the study of evaluation in academic weblogs. Text \& Talk, 32(2), 145-165.

Pipino, L. L., Lee, Y. W., \& Wang, R. Y. (2002). Data quality assessment. Communications of the ACM, 45(4), 211-218. doi.org/10.1145/505248.506010

Pow, J., Li, S. C., \& Fung, A. C. W. (2009). Students' inquiry learning in the Web 2.0 age. In A. Tatnall, A. Visscher, A. Finegan, \& C. O’Mahony (Eds.), Evolution of information technology in educational management (pp. 107-116). Boston, MA: Springer.

Rieh, S. Y. (2002). Judgment of information quality and cognitive authority in the Web. Journal of the American Society for Information Science and Technology, 53(2), 145-161.

Saper, C. (2006). Blogademia. [Electronic Version]. Reconstruction, 6(4), 1-15. Retrieved from http://reconstruction.eserver.org/064/saper.shtml 
Straub, E. (2009). Understanding technology adoption: Theory and future directions for informal learning. Review of Educational Research, 79(2), 625-649. doi.org/10.3102/0034654308325896

Strong, D. M., Lee, Y. W., \& Wang, R. Y. (1997a). 10 potholes in the road to information quality. Computer, 30(8), 38-46. doi.org/10.1109/2.607057

Strong, D. M., Lee, Y. W., \& Wang, R. Y. (1997b). Data quality in context. Communications of the ACM, 40(5), 103-110. doi.org/10.1145/253769.253804

Wang, R. Y. and Strong, D. M. (1996). Anchoring data quality dimensions in ontological foundations. Communications of the ACM, 39(11), 86-95.

Wand, Y., \& Wang, R. Y. (1996). Anchoring data quality dimensions in ontological foundations. Communications of the ACM, 39(11), 86-95. doi.org/10.1145/240455.240479

Warwick, C., Rimmer, J., Blandford, A., Gow, J., \& Buchanan, G. (2009). Cognitive economy and satisficing in information seeking: A longitudinal study of undergraduate information behavior, Journal of the American Society for Information Science and Technology, 60(12), 2402-2415.

Wei, L., \& Zhang, M. (2008). The impact of Internet knowledge on college students' intention to continue to use the Internet. Information Research, 13(3), paper 348. Retrieved from http://InformationR.net/ir/13-3/paper348.html

Wiley, J., Goldman, S. R., Graesser, A. C., Sanchez, C. A. Ash, I. K., \& Hemmerich, J. A. (2009). Source evaluation, comprehension, and learning in Internet science inquiry tasks. American Educational Research Journal, 46(4), 1060-1106. doi.org/10.3102/0002831209333183

Yusoff, Y., Muhammad, Z., Zahari, M., Pasah, E., \& Robert, E. (2009). Individual differences, perceived ease of use, and perceived usefulness in the E-Library usage, Computer and Information Science, 2(1), 76-83.

Zmud, R. W. (1978). An empirical investigation of the dimensionality of the concept of information. Decision Sciences, 9(2), 187-195. doi.org/10.1111/j.1540-5915.1978.tb01378.x

Corresponding author: Jacky Pow, jackypow@hkbu.edu.hk

Australasian Journal of Educational Technology (C) 2015.

Please cite as: Pow, J., \& Li, S.C. (2015). The effect of students’ perceptions of Internet information quality on their use of Internet information in inquiry-based learning. Australasian Journal of Educational Technology, 31(4), 439-457. 